\title{
CANOPY DENSITY MAPPING ON ULTRACAM-D AERIAL IMAGERY IN ZAGROS WOODLANDS, IRAN
}

\author{
Y. Erfanifard ${ }^{\mathrm{a}, *}$, Z. Khodaee ${ }^{\mathrm{a}}$ \\ ${ }^{a}$ Dept. of Desert Management, College of Agriculture, Shiraz University, Shiraz, Iran - erfanifard@ shirazu.ac.ir, \\ khodaeizohreh@yahoo.com
}

KEY WORDS: Canopy density map, kNN, UltraCam-D imagery, Woodland, Zagros.

\begin{abstract}
:
Canopy density maps express different characteristics of forest stands, especially in woodlands. Obtaining such maps by field measurements is so expensive and time-consuming. It seems necessary to find suitable techniques to produce these maps to be used in sustainable management of woodland ecosystems. In this research, a robust procedure was suggested to obtain these maps by very high spatial resolution aerial imagery. It was aimed to produce canopy density maps by UltraCam-D aerial imagery, newly taken in Zagros woodlands by Iran National Geographic Organization (NGO), in this study. A 30 ha plot of Persian oak (Quercus persica) coppice trees was selected in Zagros woodlands, Iran. The very high spatial resolution aerial imagery of the plot purchased from NGO, was classified by kNN technique and the tree crowns were extracted precisely. The canopy density was determined in each cell of different meshes with different sizes overlaid on the study area map. The accuracy of the final maps was investigated by the ground truth obtained by complete field measurements. The results showed that the proposed method of obtaining canopy density maps was efficient enough in the study area. The final canopy density map obtained by a mesh with $30 \mathrm{Ar}\left(3000 \mathrm{~m}^{2}\right)$ cell size had $80 \%$ overall accuracy and 0.61 KHAT coefficient of agreement which shows a great agreement with the observed samples. This method can also be tested in other case studies to reveal its capability in canopy density map production in woodlands.
\end{abstract}

\section{INTRODUCTION}

Zagros woodlands cover a vast area of Zagros mountain ranges stretching from Piranshahr (Western Azerbaijan Province), NW Iran, to the vicinity of Firoozabad (Fars Province) in SW Iran, having an average length and width of 1,300 and $200 \mathrm{~km}$, respectively. Classified as semi-arid, Zagros woodlands cover 5 million hectares and consist $40 \%$ of Iran's forests (SaghebTalebi et al. 2003).

The signs of agriculture in these woodlands date back to $9000 \mathrm{BC}$ and some studies show the old history of its vegetation cover (Djamali et al., 2009). Detailed and accurate thematic maps of these woodlands are needed for assessment of the flora and faunal biodiversity as well as for their sustainable management. The conventional way of ground measurements for map production can be tedious and time-consuming, whilst the use of geographical information system (GIS) and remote sensing may speed up the process and provide for a more efficient option.

Thematic maps show the spatial distribution of identifiable earth surface features and it provides an informational description over a given area. Image classification is the process used to produce thematic maps from remote sensing imagery (Schowengerdt, 2007). Canopy density maps, as a specific type of thematic maps, are important data that can be derived from remote sensing imagery. These maps can be applied in assessing and monitoring forest changes (e.g. Wang et al., 2004; Thomson et al., 2007; Zeng et al., 2008).

Forest density defined as the percent area occupied by the vertical projection of tree crowns, is a common concept in forestry and of wide interest in both scientific studies and political decisions (Rudnicki et al., 2004; Suganuma et al,. 2006).

* Postal Code: 7144165186, Shiraz, Iran. Tel. +98 7116138162
Also it has recently become an important part of forest inventories (Wiliams et al. 2003; Rautiainen et al. 2005; Korhonen et al. 2006; Zeng et al., 2008). Canopy density is completely related to the shape of a tree crown and its vertical projection, so automatic classification of remote sensing imagery using pixel-based approaches and their spectral content are not well suited for canopy cover mapping.

In most researches, the mentioned definition was not taken in to consideration (e.g. Nandy et al., 2003; Zeng et al., 2008) and in other studies that remote sensing imagery was applied for obtaining canopy density maps, the canopy reflectance and related indices (AVI, NDVI and etc) were utilized for classification (e.g. Roy et al., 1996; Rikimaru et al., 2002; Azizi et al., 2008; Panta et al., 2008).

However, the definition of canopy density was considered in a few studies. In FRA2000 programme, the canopy density was defined as the fraction of 1 square $\mathrm{km}$ cells covered by canopy of trees in field measurements. Also Kral (2009) measured different canopy classes in 1000 square $\mathrm{m}$ cells in field survey and on color-infrared orthophotos. Carreiras et al. (2006) used dot grid method to distinguish five canopy cover classes of interest in $120 \mathrm{~m} \times 120 \mathrm{~m}$ square plots.

Estimating canopy cover over large forest and woodlands has been a focal point in the remote sensing community since the launch of satellites and public availability of resulting data. Additionally, these data also facilitate spatial delineation of vegetation density maps through various techniques using satellite imagery in conjunction with GIS and phytosociological ground data. In addition, these data techniques can be combined for spatial prediction and modeling of the vegetation's biophysical properties. With better spectral and spatial resolution of satellite, higher scale of interpretation and more 
extensive ground truthing led to improvement in estimation of forest cover data in the recent years (Franklin, 2001; Schowengerdt, 2007).

The National Geographic Organization (NGO), Iran, is taking very high spatial resolution aerial imagery by UltraCamD (UCD) camera that can be applied in different activities including forest mensuration. Because of the high spatial resolution of the imagery, landscape features such as shrubs, anthropogenic features, and trees in woodlands are readily apparent and visually identifiable and they can be measured directly on the imagery.

Despite previous studies, it still is vague for some scientists how to measure the canopy density in a unit area. The objective of this study is to develop a methodology for automatic derivation of canopy density maps applying very high spatial resolution (VHSR) airborne UCD imagery in Zagros woodlands, Iran. A robust procedure is also suggested to determine the optimal unit area for canopy density measurement.

\section{METHODOLOGY}

\subsection{Study Area}

The study site is located in Yasuj city, Kohgiluye-vaBoyerAhmad province, Iran, between $51^{\circ} 36^{\prime} 42^{\prime \prime}$ to $51^{\circ} 37^{\prime} 01^{\prime \prime}$ $\mathrm{E}$ and $30^{\circ} 37^{\prime} 31^{\prime \prime}$ to $30^{\circ} 37^{\prime} 51^{\prime \prime} \mathrm{N}$ (Fig. 1).

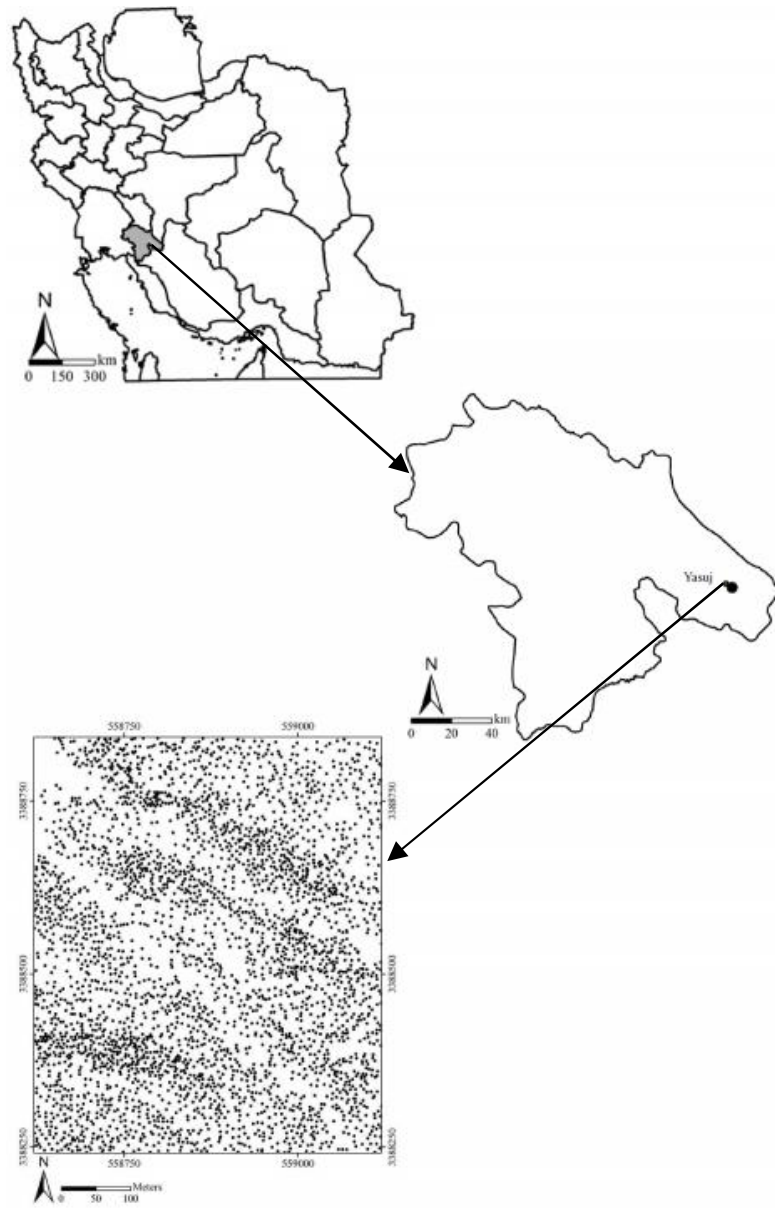

Figure 1. Map identifying the location of Kohgiluye-vaBoyerAhmad province relative to Iran and the study area.
The minimum and maximum elevations are 1150 and $1380 \mathrm{~m}$, respectively. The mean annual precipitation and temperature are $460 \mathrm{~mm}$ and $24.6{ }^{\circ} \mathrm{C}$, respectively. A 30 ha plot $(500 \times 600 \mathrm{~m})$ fully covered with Persian oak (Quercus persica) as the most frequent tree species in Zagros woodlands, was selected for this research (Fig. 2). Most of the trees have coppice structure in this region with lots of branches and round crowns (Fig. 3).

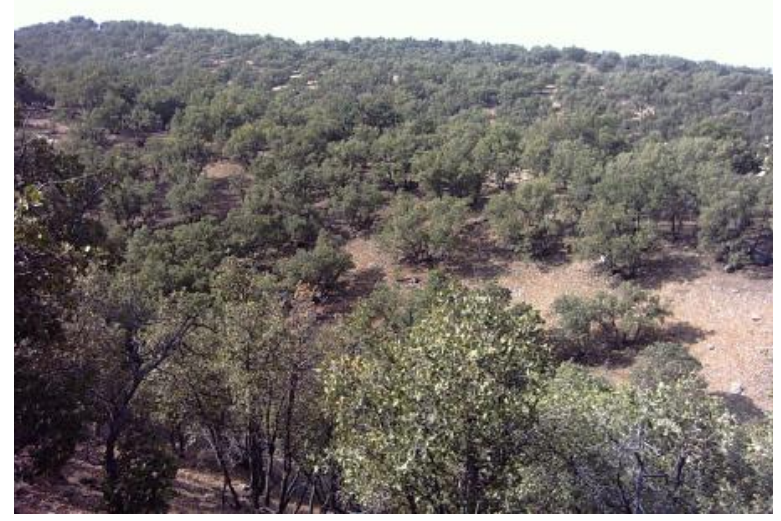

Figure 2. The study area covered with Persian oak trees.

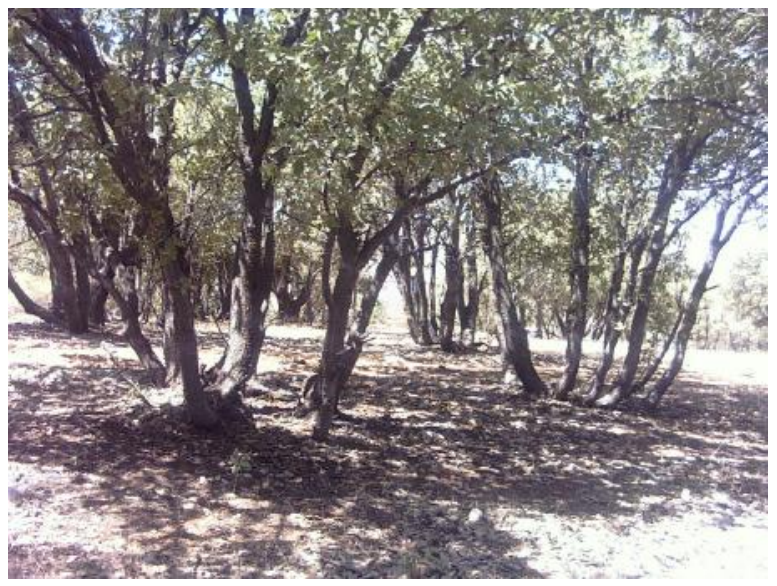

Figure 3. Coppice structure of Persian oak trees in the study area.

\subsection{UCD imagery}

UCD VHSR aerial imagery newly taken in Iran was applied in this study to investigate its potential to measure canopy cover in Zagros woodlands. As these data has very high spatial resolution $(0.06 \mathrm{~m})$, it is expected to detect and extract crown boundaries of trees more precisely compared to other high-resolution remote sensing data, available in Iran (e.g. $\mathrm{B} \& \mathrm{~W}$ aerial photographs, satellite imagery like IKONOS and Quickbird).

The FL (Focal Length) and IFOV (Instant Field of View) of camera used to take this imagery are $101.4 \mathrm{~mm}$ and $37^{\circ}$, respectively. The resulting imagery has $7500 \times 11500$ pixels with 5 panchromatic, RGB and infrared bands. The height of the plane carrying the camera is about $700 \mathrm{~m}$ a.s.l. 
Compared to common $\mathrm{B} \& \mathrm{~W}$ aerial photographs taken in Iran since 1955, the features in UCD imagery have less displacement due to its small IFOV, the covered area (about 50 ha) and the flying height. This characteristic makes it a suitable data for vertical measurement of features like trees.

Although, it should be mentioned that the size of each image file is so big (more than $400 \mathrm{mb}$ ) that makes it difficult to work with them in large areas and big projects. The applied imagery of the study area was taken in 22 Dec. 2008 and its scale is 1:7000 (Fig. 4).

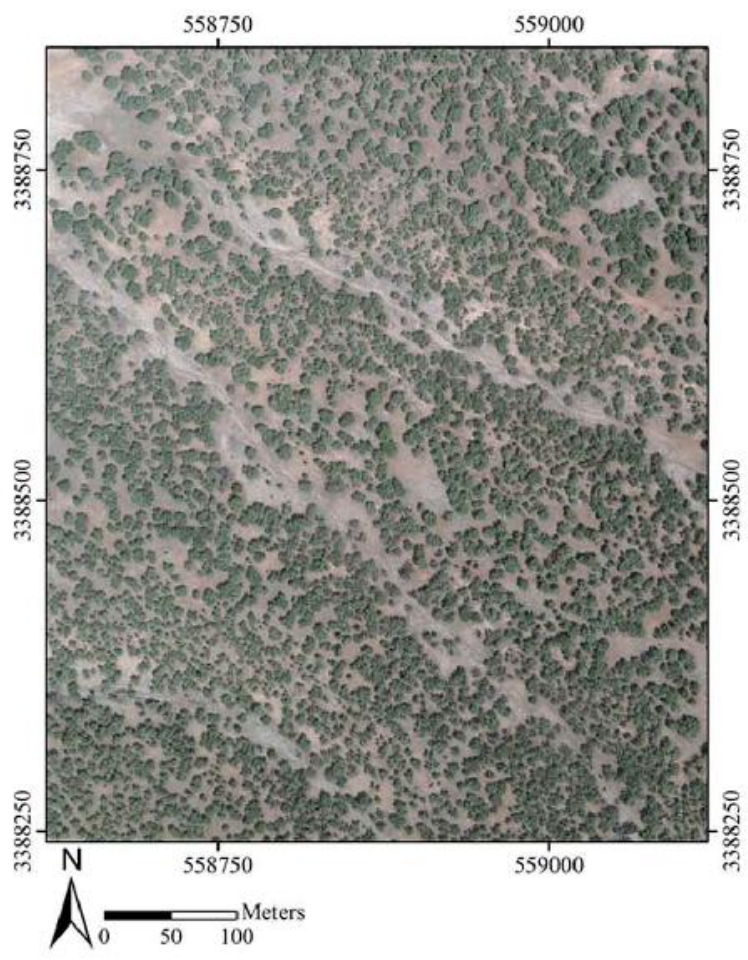

Figure 4. The UCD imagery of the study area.

\section{3 image classification}

Traditional pixel-based image classification approaches have some limitations with the use of very high spatial resolution imagery. Object-oriented classification method, as an alternative to pixel-based approach, is considered to overcome the limitations. Object-oriented classification method analyzes groups of contiguous pixels as objects instead of using the conventional pixel-based classification unit (Yu et al., 2006; Li and Cheng, 2009).

In addition, with spectrally homogeneous segments of images, both spectral values and spatial properties, such as size and shape, can be explicitly utilized as features for further classification. The basic idea of this process is to group the spatially adjacent pixels into spectrally homogenous objects first, and then conduct classification on objects as the minimum processing units (Yu et al., 2006; Gamanya et al., 2007).

K-Nearest Neighbour $(\mathrm{kNN})$ widely used because of the implementation simplicity, the clarity of theory and the excellent classification performance is a common classification method. It can achieve high accuracy in the classification of high resolution remote sensing images ( $\mathrm{Li}$ and Cheng, 2009).
The UCD imagery of the study area was classified by kNN classification algorithm using training sets and testing sets carefully selected on the imagery. Also different nearest neighbours including $\mathrm{k}=1$ to $\mathrm{k}=10$ were applied and the results were tested comparing to the real canopy cover of the study area to find out the most suitable one. Two main classes of tree crowns and other features were separated on the UCD imagery by kNN classification technique.

\section{4 map production}

It was necessary to define the unit that canopy density should be measured in it. As it was vague for the authors which size $(1$ square $\mathrm{km}$ or $120 \times 120$ square plots) was suitable for canopy density measurements, different sizes $\left(0.5 \operatorname{Ar}\left(50 \mathrm{~m}^{2}\right)\right.$ to $350 \mathrm{Ar}\left(35000 \mathrm{~m}^{2}\right)$ ) were tested to find the most suitable one due to their KHAT coefficient and overall accuracy of the maps.

Classifying the imagery by kNN technique into two main classes of "tree crown" and "others", meshes with different cell sizes ranging from 0.5 Ar to $350 \mathrm{Ar}$ were overlaid the classified imagery. The canopy cover of each cell is determined related to its surface area and the final mesh is classified due to the defined classes by IRAN Forests, Rangelands and Watershed Organization (FRWO). The tree map layer was generated from very high spatial resolution UCD imagery and therefore the best accuracy assessment is the use of field validation methods. Confusion matrixes made between field measurements and maps were applied to assess the accuracy of the final canopy cover maps by overall accuracy and KHAT coefficient (Zimmerman et al., 2010; Paine and Kiser, 2012).

\section{RESULTS}

The suggested procedure produced the canopy density map of the study area applying UCD VHSR aerial imagery. It was necessary to orthorectify the imagery before classification so the UCD imagery was firstly orthorectified by 1:25000 topographic maps and 6 points with 0.28 cell RMSE (X RMSE $=0.26$ cells and $\mathrm{Y}$ RMSE $=0.09$ cells).

It was vague for the authors which $\mathrm{k}$ is the most suitable one and comparing the results of different $\mathrm{k}^{\text {th }}$ nearest neighbour ( 1 to 10 ), it was concluded that $\mathrm{k}=4$ is the most suitable one with no significant difference between the estimated canopy cover by UCD image classification $(48.7 \%)$ and the ground truth $(48.5 \%)(\mathrm{t}=0.04$ at 0.05 level$)$. As mentioned, the UCD imagery was classified by kNN classification technique $(\mathrm{k}=4)$ into two classes of tree crowns and other features (Fig. 5).

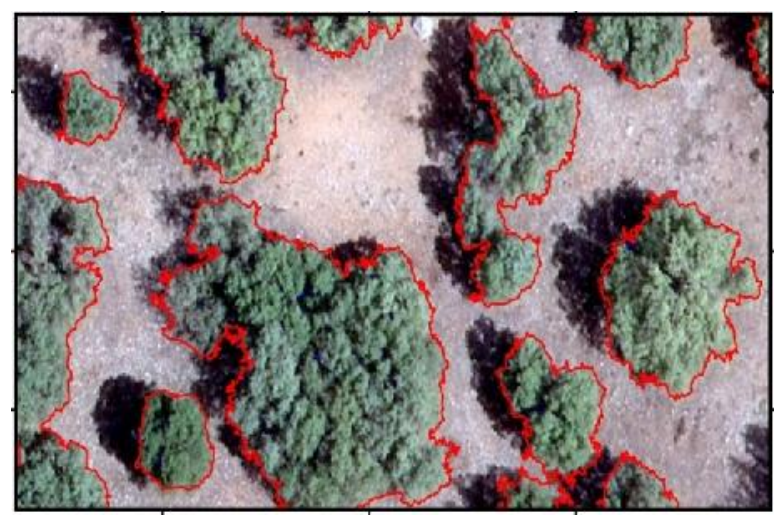

Figure 5. A part of UCD imagery classified by $\mathrm{kNN}$ technique with $\mathrm{k}=4$. 
Overlaying different meshes with different cell sizes on the classified UCD imagery and ground truth, the canopy density of each cell was calculated and compared to each other. The overall classification accuracy and the KHAT coefficient of agreement of different meshes with different cell sizes are shown in Fig. 6 and 7 obtained by cell-by-cell comparison of the ground truth and unclassified canopy density maps.

As it was expected, the increasing trend of overall accuracy and KHAT coefficient started in the 0.5 Ar map and continued up to the map with $40 \mathrm{Ar}$ cells. This increasing trend became flat after the 40 Ar map.

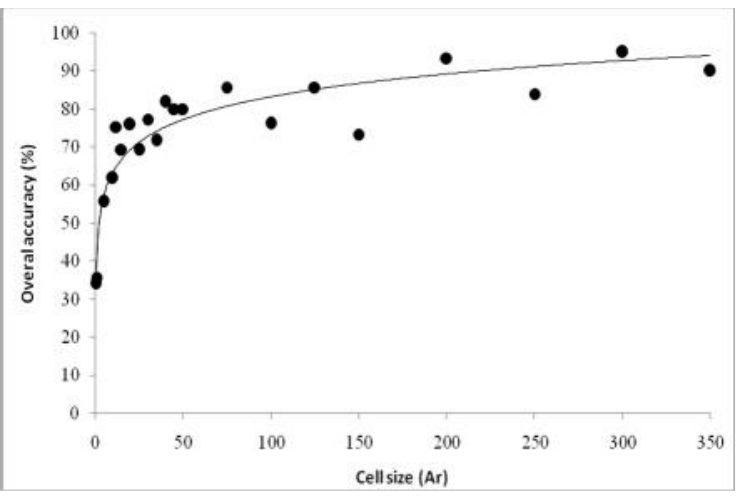

Figure 6. Overall accuracy of all canopy density maps.

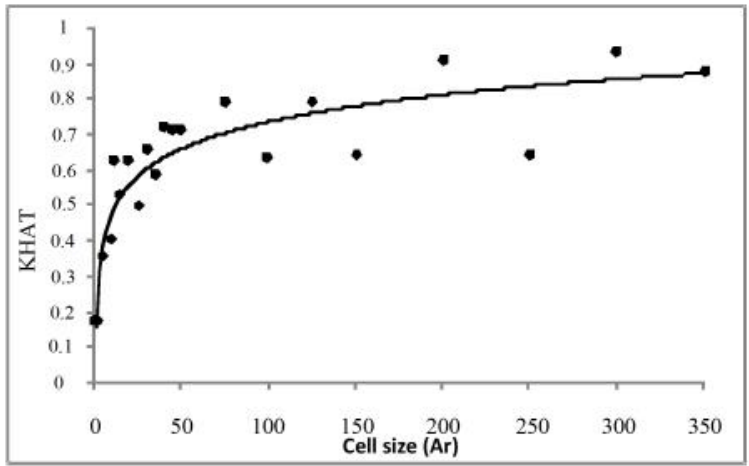

Figure 7. KHAT coefficient of all canopy density maps.

As observed in Fig. 6 and 7; the trend of overall accuracy and KHAT coefficient started to be plane at $10 \mathrm{Ar}$ mesh and the line became plane at $40 \mathrm{Ar}$ mesh in the both figures. Consequently, 8 maps with 10, 12, 15, 20, 25, 30, 35 and $40 \mathrm{Ar}$ were selected for further studies.

It was aimed to find the least size with the best accuracy and agreement with the ground truth. Between all of the maps, the mentioned eight maps were chosen to analyse their overall accuracies and KHAT coefficients after filtering the boundaries of canopy density classes. Filtering the selected maps to smooth the boundaries, their overall accuracy and KHAT coefficient were calculated again by confusion matrix method (Table 1).

A systematic dot grid with 30 points (in a $100 \times 100 \mathrm{~m}$ mesh) were overlaid on the filtered 8 canopy density maps and the ground truth to obtain the confusion matrix applied to calculate the mentioned indices. In each point, a circular $800 \mathrm{~m}^{2}$ plot was overlaid on the ground truth and its canopy density was calculated and compared with the final canopy density maps obtained from UCD aerial imagery to figure out if it was correct and the put the results in the confusion matrix.

\begin{tabular}{ccc}
\hline Cell size $($ Ar $)$ & KHAT coefficient & Overall accuracy $(\%)$ \\
\hline 10 & 0.23 & 56.7 \\
12 & 0.57 & 76.7 \\
15 & 0.43 & 70 \\
20 & 0.53 & 73.3 \\
25 & 0.41 & 66.7 \\
30 & 0.61 & 80 \\
35 & 0.49 & 73.3 \\
40 & 0.59 & 80 \\
\hline
\end{tabular}

Table 1 . The analyses of final canopy density maps.

As observed in Table 1, the overall accuracy and KHAT coefficient of the investigated maps improved with increasing the cell size of the mesh from $10 \mathrm{Ar}$ to $40 \mathrm{Ar}$. The lowest overall accuracy and KHAT coefficient were in the map resulted from $10 \mathrm{Ar}$ mesh (56.7\% and 0.23 respectively). The trend of improvement continued till 12 Ar mesh and after that, it fluctuated smoothly and the amounts of the indices went up and down till 40 Ar mesh.

The results presented in Table 1 also showed that the canopy density map with 30 Ar cell size (80\% overall accuracy and 0.61 KHAT coefficient) was the most suitable map to show the canopy density of the study area (Fig. 8).
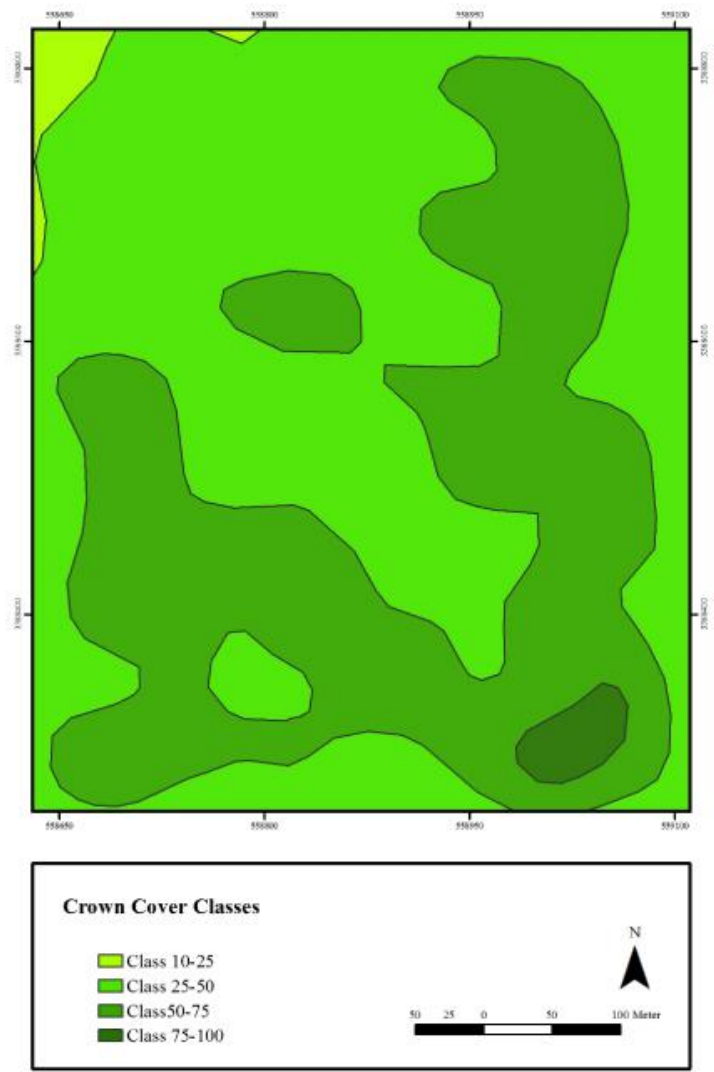

Figure 8. Canopy density map with 30 Ar cell size. 


\section{CONCLUSION}

The canopy density map of Zagros woodlands is one of the most important datasets necessary in sustainable management of these valuable woodlands (Jazirehi and Ebrahimi Rostaghi, 2003.). In order to obtain this map, an intensive and laborious field work is inevitable which is not possible in most cases, e.g. Zagros woodlands because of their vastness and being spread in mountainous areas. Remotely sensed imagery can therefore be helpful in this circumstance (Franklin, 2001; Schowengerdt, 2007). This research was aimed to produce canopy cover maps of these woodlands applying UltraCam-D VHSR aerial imagery which is newly taken by NGO, Iran. A robust procedure was consequently suggested in this research for this purpose.

In the first step, the VHSR imagery was classified by $\mathrm{kNN}$ technique to distinguish two classes of tree crowns and other features. As mentioned above, it was vague for the authors which nearest neighbour was the most suitable one for the image classification. In order to find this point out, different nearest neighbours ( $k=1$ to 10$)$ were tested and the results showed that $\mathrm{k}=4$ was the best for the imagery of the study area. In different researches, different nearest neighbours were applied depending on their subjects (e.g. Holmstrom, 2002; Yu et al., 2006; Thessler et al., 2008; Guru et al., 2010) and the comparison between the ground truth and canopy cover resulted from different $\mathrm{ks}$ showed that $\mathrm{k}=4$ was the best choice in this research. It is so concluded that optimal $\mathrm{k}$ in this classification method depends on the remote sensing data used and the objectives of the study and it is not always possible to prescribe the optimal $\mathrm{k}$ for all studies.

As observed in Fig. 6 and 7; the overall accuracy and KHAT coefficient of the maps improved as the cell size of the meshes increased. This happened because as the cell size was increase, less cell numbers were in the mesh and there were more similarities between the ground truth and the produced canopy density map. We selected eight of these maps as explained above (Table 1) because we wanted to select the first map with optimum indices observed. Although the accuracy of the maps increased with increasing the cell sizes (Fig. 6 and 7), it was aimed to find a balance between the accuracy and the classes of canopy density on the maps.

As observed in Table 1, the overall accuracy and KHAT coefficient of the investigated maps improved with increasing the cell size of the mesh either and the lowest overall accuracy and KHAT coefficient were in the $10 \mathrm{Ar}$ map $(56.7 \%$ and 0.23 respectively). This happened because of the great number of canopy density classes compared to other maps in Table 1 . As the number of the canopy density polygons increased, the probability of misclassifications increased too.

It also should be mentioned that each one of these maps in Table 1 could have different numbers of density classes detected depending on the cell size of the applied meshes. The 10 Ar map, for example, had all canopy density classes (0-5\%, $5-10 \%, 10-25 \%, 25-50 \%, 50-75 \%$ and $75-100 \%$ ) although this was not the case for the $40 \mathrm{Ar}$ map. It was concluded that the results showed that the 30 Ar cell size (80\% overall accuracy and 0.61 KHAT coefficient) was the most suitable map (Fig. 8) but other maps could be applicable due to the objective of the study. If it was needed to find all of the density classes in an area (for management practices like plantations), maps with small cell size are suggested but if the accuracy of the final map was more important for the users, the maps with optimal indices of overall accuracy and KHAT are proposed.
It was also concluded that the UCD VHSR imagery could produce a precise map of the tree crowns in the study area due to its high spatial resolution. In previous studies, remotely sensed datasets with less spatial resolution were applied for this objective (e,g, Naseri et al., 2004; Carreiras et al., 2006; Mallinis et al., 2007; Azizi et al., 2008).

It was explained the one of the advantages of the proposed method to produce canopy density maps in this study was that users can choose different maps according to their needs. As the cell size decreases, more detailed parts of each density class can be detected on the map. Another advantage of this method was that the definition of canopy density was considered producing canopy density maps. It was ignored in some other studies. It helps users make management decisions in woodlands more efficiently.

According to the results, it was concluded that the proposed approach was efficient enough in the study area and it is suggested to test the method in other parts of Zagros woodlands to prove its capability in future researches.

\section{REFERENCES}

Azizi, Z., Najafi, A. and Sohrabi, H., 2008. Forest canopy density estimating, using satellite images. The International Archives of the Photogrammetry, Remote Sensing and Spatial Information Sciences. Vol. XXXVIII. Part B8. Beijing 2008, pp. 1127-1130.

Carreiras, J., Pereira, J. and Pereira, J., 2006. Estimation of tree canopy cover in evergreen oak woodlands using remote sensing. Forest Ecology and Management, 223, pp. 45-53.

Djamali, M., De Beaulieu, J., Miller, N.F., Ponel, V.A., Ponel, Ph., Lak, R., Sadeddin, N. and Akhani, H., 2009. Vegetation history of the Zagros mountains during the last five millennia; a pollen record from the Maharlou lake, Fars province, Iran. Vegetation History and Archaeobotany, 18(2), pp. 123-136.

Franklin, S.E., 2001. Remote sensing for sustainable forest manangment. Lewis Publishers, pp. 407.

Gamanaya, R., Maeyer, P. and Dapper, M., 2007. An automated satellite image classification design using object-oriented segmentation algorithms, A move towards standardization. Expert Systems with Applications, 32, pp. 616-624.

Guru, D.S., Sharath, Y.H. and Manjunath, S., 2010. Texture features and $\mathrm{KNN}$ in classification of flower images. National Seminar on Recent Trends in Image Processing and Pattern Recognition (RTIPPR), 15-16 Febuary 2010, Bidar. India, pp. 21-29.

Holmstrom, H., 2002. Estimation of single-tree characterisics using the KNN method and plotwise aerial photograph interpretations. Forest Ecology and Management, 167, pp. 303314.

Jazirehi, M., and Ebrahimi Rostaghi, M., 2003. Zagros silviculture. Tehran University Press, pp. 560.

Korhonen, L., Korhonen, K.T., Rautiainen, M. and Stenberg, P., 2006. Estimation of forest canopy cover: a comparison of field measurement techniques. Silva Fennica, 40(4), pp. 577588.

Kral, K., 2009. Classification of current vegetation cover and Alpine treeline ecotone in the Praded Reserve (Czech Republic), using remote sensing. Mountain Research and Development, pp. 177-183.

Li, Y. and Cheng, B., 2009. An improved k-nearest neighbor algorithm and its application to high resolution remote sensing image classification. 17th International Conference on Geoinformatics, USA, pp. 1-4. 
Mallinis, G., Koutsias, N., Tsakiri-Strati, M. and Karteris, M., 2007. Object-based classification using vegetation polygons in a Mediterranean test site. ISPRS Journal of Photogrammetry \& Remote Sensing, 63, pp. 237-250.

Nandy, S., Joshi, P.K. and Das, K.K., 2003. Forest Canopy density stratification using biophysical modeling. Journal of the Indian Society of Remote Sensing, 31(4), pp. 291-297.

Naseri, F., Darvishsefat, A.A., Sobhani, H. and Namiranian, M., 2004. An evaluation of the potential of Landsat ETM+ for forest density mapping in arid and semi-arid regions. Iranian Journal of Natural Resources, 57(1), pp. 109-119.

Paine, D. and Kiser, J., 2012. Aerial photography and image interpretation. John Wiley \& Sons, Inc, pp. 632.

Panta, M., Kim, K. and Joshi, Ch., 2008. Temporal mapping of deforestation and forest degradation in Nepal: Applications to forest conservation. Forest Ecology and Management, 256, pp. 1587-1595.

Rautiainen, M., Stenberg, P. and Nilson, T., 2005. Estimating canopy cover in Scots pine stands. Silva Fennica, 39 (1), pp. 137-142.

Rikimaru, A., Roy, P.S. and Miyatake, S., 2002. Tropical forest cover density mapping. Tropical Ecology, 43(1), pp. 39-47.

Roy, P.S., Sharma, K.P. and Jain, A., 1996. Stratification of density in dry deciduous forest using satellite remote sensing digital data-An approach based on spectral indices. Bioscience, 21(5), pp. 723-734

Rudnicki, M., Silins, U. and Lieffers, V., 2004. Crown cover is correlated with relative density, tree slenderness and tree height in Logepole pine. Journal of Forest Science, 50, pp. 356-363.

SaghebTalebi, K., Sajedi, T., and Yazdian, F., 2003. Forests of Iran. Iranian Research Institute of Forests and Rangelands, pp. 95.

Schowengerdt, R.A. 2007. Remote sensing: models and methods for image processing. Academic Press, pp. 558.

Thessler, S., Sesnie, S., Ramos Bendana, Z.S. and Ruokolainen, 2008. Using KNN and discriminant alalyses to classify rain forest types in a Landsat TM image over northern Costa Rica. Remote Sensing of Environment, 112, pp. 2485-2494.

Suganuma, H., Abe, Y., Taniguchi, M., Tanouchi, H., Utsugi, T. and Yamada, K., 2006. Stand niomass estimation method by canopy coverage for application to remote sensing in an arid area of Western Ausralia. Journal of Forest Ecology and Manangment, 222, pp. 75-87.

Thomson, A.G., Manchester, S.J., Swetnam, R.D., Smith, G.M., Wadsworth, R.A., Petit, S. and Gerard, F.F., 2007. The use of digital aerial photography and CORINE-derived methodology for monitoring recent and historic changes in land cover near UK Natura 2000 sites for the BIOPRESS project. International Journal of Remote Sensing, 28 (23), pp. 5397 - 5426

Wang, L, Sousa, W.P and Gong, P, 2004. Integration of objectbased and pixel-based classification for mapping mangroves with IKONOS imagery. International Journal Remote Sensing, 25, pp. 5655-5668.

Williams, M.S., Patterson, P.L. and Mowrer, H.T., 2003. Comparison of ground sampling methods for estimating canopy cover. Forest Science, 49(2), pp. 235-246.

Yu, Q., Gong, P., Cllnton, N., Blglng, G., Kelly, M., and Schlrokauer, D., 2006. Object-based detailed vegetation classification with airborne high spatial resolution remote sensing imagery. Journal of Photogrammetric Engineering \& Remote Sensing, 72(7), pp. 799-811.

Zeng, Y., Schaepman, M.E., Wu, B., Bruin, S. and Clevers, J., 2008. Change detection of forest crown closure using an inverted geometric-optical model and scaling. The International Archives of the Photogrammetry, Remote Sensing and Spatial
Information Sciences. Vol. XXXVII. Part B7. Beijing 2008, pp. $1-5$.

Zimmerman, P.L. and Liknes, G.C., 2010. The role of misclassification in estimating proportion and an estimator of misclassification probability. International Journal of Mathematical and Computational Forestry \& NaturalResource Sciences, 2(2), pp. 78-85. 